\title{
An Empirical Assessment of UK Economic Performance in the Context of Brexit: An EU Wide Comparison
}

\author{
Murat PÜTÜN ${ }^{1}$ \\ Semin PAKSOY2
}

\author{
https://orcid.org/0000-0002-8920-7555 \\ https://orcid.org/0000-0003-1693-0184
}

\begin{abstract}
This paper investigates overall well-being of the UK economy in comparison with other EU member countries-prior to 2015 referendum. The results will help to comprehend the very nature of the exit decision in this light. This work to a certain extent expected to help establish whether the decision taken at the referendum was more reflection of a political nature that accommodated partisan bias- or- rather it was based on the public concerns stemming from economic considerations. This empirical research employs PROMETHEE method which is one of the best known multi criteria methods. The alternatives in the comparison matrix are comprised of $28 \mathrm{EU}$ member countries and the criteria are comprised of nine criteria. The overall performance is the combination of fundamental indicators most of which-one way or another-were related to the political debate on the eve of referendum.
\end{abstract}

Keywords: PROMETHEE method, European economic integration, Brexit referendum, UK economy, Financial crisis, Single market.

\section{INTRODUCTION}

In 2014, referendum decision of strategic importance was taken by then Prime Minister David Cameroon amid the sentiments of raising concerns. Political campaigns in favour of leaving EU that often came up with populous rhetoric; the majority decision was for leaving EU, yet with a relatively narrow margin of "yes" votes. The themes like legitimate migration coming from rest of the EU, the UK's financial contribution to the EU, unemployment had to contribute to the anti European sentiments. Among others, these underlined issues were the sources of resentment in UK-thought to be of economic nature- paving the way for Brexit.

Procedure for leaving the EU is based on the Article 50 of the Treaty on the EU, which holds a negotiation period of up to two years to settle down a leaving agreement. The reality of Brexit- at least in the shortrun-can pragmatically be translated into a predictive framework in suggesting that this whole process of separation would substantially undermine the European integration process; and further efforts for deeper integration and collobration. Already, this process has sparked off some soul searching at some political circles about the relevance of the exit referendum for some other EU countries with the UK example on the table. Departing from this juncture, this paper investigates overall well-being of the UK economy in relation with the other EU member countries-prior to 2015 referendum. The results will help comprehend the very nature of the exit decision in this light.

Formation of the European Union is the result of a continuous integration project that had started as early as 1958 , formerly known as European Community (EC) or European Economic Community (EEC). Ever since then, the European integration project had been gradually achieving considerable progress and had been growing consistently despite of the fierce challenges

\footnotetext{
'Çukurova University, Faculty of Economics and Administrative Sciences. Economics Dept, Balcalı campus, 01330, Adana, Turkey, mputun@cu.edu.tr

${ }^{2}$ Çukurova University, Faculty of Economics and Administrative Sciences, Econometrics Dept. Balcalı campus, 01330, Adana, Turkey, spaksoy@cu.edu.tr
} 
encountered along the process up to this day. EEC had been established on the grounds of ambitious economic objectives and discharged number of relevant crucial political entities to give shape and form to the European integration process, over the time. In fact, initial project of designing a United Europe was not merely driven by economic agenda but predominantly motivated by ambitious political desires for post-war settlement in Europe. The post -war aspirations in totalwere to create an EC by drawing as many participants as from the European continent for establishing and maintaining a permanent peace in Europe and possibly in the whole world. These objectives have been largely realized despite the some setbacks encountered during the ongoing process.

Despite the fact that the UK has been in support of political stability and peace in Europe since the end of the Second World War, has not championed European ideals as a staunch supporter of European integration-either in political or in economic terms. However, the decision to trigger a referendum for joining EEC was as much of a decision of political considerations as it was of an economic nature.

\section{LITERATURE}

Upon the decision to take the UK to a referendum, research on Brexit has been steadily growing in various aspects. The economic consequences or cost benefit considerations have generally highlighted the area of research. EC (2011) analysis the likely consequences of the possible case of UK leaving the EU with a particular focus on the the costs and benefits of EU integration for the member countries. The projection of loss for UK in the case of possible Brexit is highlighted. HM Treasury (2016) reviews the alternatives for EU membership and alternative trade regimes, treating a possible regime change rather prudently. It contends that all the available alternatives have the implications of attached costs; therefore trade exchanges with rest of the EU would become more costly than used to be.

This work further eloborates potential investment impact, challenging that alternatives available would not permit UK to have full access to the EU single market and in return UK would become less attractive country for incoming foreign direct investment (FDI). PwC (2016), a report concerning Brexit, focuses on the broader implications of UK leaving the EU and alternatives as result of separation have also been addressed. The possibilities regarding trade, investment and labour are reviewed under the context of
Brexit. Brexit has larger financial markets implications and can have strong effect on markets to generate volatility. Saunders et al. (2016) question such aspects suggesting that market risks are the important dimensions of economic consequences of UK leaving the EU. The possible implications across the economies are the source of this analysis. Switzerland has never favoured tighter economic and financial integration with the rest of the EU, but always has concentrated on Europe and EU as important economies and entity to have moderate ties with. As an alternative financial regime, City of London (2013) looks into the intricate nature of Swiss partnership without having to become a full member. Emmerson et al.(2016), reports on the likely implications of a possible Brexit on UK's fiscal policy domain in the future. House of Commons (2013) highlights British view and interests regarding possible future disintegration long before the referendum decision. UK have opted-out of Economic and Monetary Union (EMU) while remaining as a member of EU in ensuring a certain degree of authonomy for the Bank of England. Bank of England (2015) accounts for the extent of the mandate of Bank of England under the status of EU membership whose stringent rules tend to limit its competence.

The rest of the structure of this article is as follows: Part two presents the research methodology and identifies research objectives. PROMETHEE method is introduced and explained as the core of empirical investigation applied by this paper. Part three presents overall results of the testing. PROMETHEE country rankings and various charts regarding countries' performances; and relevant linkages are illustrated. The findings are further analyzed and interpreted within the framework of this research thesis. Finally; Part four provides a broad conclusion of the results.

\section{RESEARCH OBJECTIVES, DATA and METHODOLOGY}

\subsection{Research Questions and Objectives}

This work includes 28 selected EU member countries' respective nine economic variables to establish its results. Letonya has not been included due to the data restriction.

Brexit has become a reality supposedly because UK's hands were tied; economic well being and social welfare were in decline. Before the referendum, campaigns were mainly organized about the claim that members of public were suffering in many domains 
because of constantly deterroriating economy, and the consequences of EU membership were to blame fort that. Political rhetoric was to follow the economic claim as if the former was detached from the latter. The UK opposition for EU policies and strategies have always been present in the political agenda but never before it had reached to this scale-where a Prime minister solemnly declared the possibility of a referendum- out of blue. The consequential decisions taken at the Maastricht Conference was a big disappoinment for the ruling UK politicians back then, yet over a time period of more than two decades, EU opposition had not been any nearer to that level. This research attempts to illuminate the following points in their due relevance with the inquiry:

First of all, up to the referendum, did economy and the public welfare in general decline noticably so that greater public suffered as result? This is the question that will be sought throught this work. Second, within its own standards, the revealed scores for each country can demonstrate their degree of overall economic health. But along with that, PROMETHEE results demonstrate the respective rankings for comparing a particular country's performance with those of other countries'. Third, regarding the extent of the alleged EU wide opposition to European integration-What basis does it represent? If the economic complaints were the core of the UK's decision, other countries might yet respond with similar outcome in the future if they were faced with the familiar hardships and challenges. Can (now a hypothetical case) it be interpreted in a way that they can also feel the brunt of disintegration? This will offer an intuiton into understanding the alleged potential risks that lie behind the EU integration as an economic and political entity. Finally, this research hopes to shed light on the general state of the UK economy in particular, and other EU countries in general. Are the economies are prospering-or the opposite? Do they display deviation between improvement and decline? How does a particular country perform in the face of particular criteria? Which are the best-which others are the worst performers? Alternatively, it can be inferred that a particular country does well with some criteria and bitter performance concerning with others. How to interpret that? How countries peform poorly with the most of criteria can intuitively be viewed through the graphical illustrations for these particular countries. It is also possible to observe the performances of countries matching with other countries' performances on the very same criterion.
By no means is it easy or possible to eliminate political influences that might have become utmost concern for some sections of the society voted in favour of leaving the EU. Therefore some degree of "political bias" can be tolerated in the argument. But it is also established that for the majority (majority of leave-camp) that line of choice would not have been transformed if the economic well-being and prosperity was the perceived and shared reality of the general public. Additionally, this process will allow the specialists and policymakers to understand the future assessment of European integration as to whether there would be enough incentive for others to leave the EU. In fact, the EU governance needs to set out strategies to consolidate the future prospect of European integration.

\subsection{Data for the Application}

This work includes 28 selected EU member countries' respective nine economic variables for the period of 2010-2015 to establish its results. Letonya has not been included due to the data restriction. The criteria (variables) used in this work are as follows:In work atrisk-of-poverty rate, unemployment, export-imports, youth unemployment, severely materially deprived people, inequality of income distribution, Gross Domestic Product (GDP), FDI net outflows (\% of GDP) and FDI net inflows (\% of GDP). Related data for the selected countries is obtained from the website of eurostat, except FDI net inflows and outflows. The data about FDI is obtained from the website of worldbank.

\subsection{PROMETHEE Method}

PROMETHEE method is one of the relatively latest introduced outranking methods. Main objective of this method is to ensure that comparison of alternatives can be easily understood by the decision maker. The method is more focused on the evaluating the alternatives depending on each criteria using new proposed preference functions of each criterion. Even though there has been many ranking methods, there still exist a lot of interests for the PROMETHEE in the literature because of its powerfully prepared algorithm and software including explanatory graphs and meaningful preference functions of the criteria.

PROMETHEE method is examined in the selection and ranking problems using the following steps (Brans \&Vincke, 1985, Dağdeviren \& Eraslan, 2008; Özdağoğlu, 2013). 
Step 1.Defining the alternatives and criteria.

The number of alternatives that are $i$ and the number of criteria that are $j$ are determined.

Step 2. Creating the initial decision matrix with the $m \times n$ dimensions where $m$ denotes the alternatives, $n$ denotes criteria. The matrix element $a_{i j}$ denotes the value of $i$ th alternative under the jth criterion.

Step 3.Selecting the suitable preference function for each criterion using the Table 1.

Tablo 1: The Preference Functions

\begin{tabular}{|c|c|c|c|c|}
\hline Type & Parameter & \multicolumn{2}{|c|}{ Function, $\boldsymbol{P}(\boldsymbol{x})$} & Meaning \\
\hline $\begin{array}{l}\text { Type I } \\
\text { (Usual) }\end{array}$ & - & $=\left\{\begin{array}{l}0, \\
1,\end{array}\right.$ & $\left.\begin{array}{l}x \leq 0 \\
x>0\end{array}\right\}$ & $\begin{array}{l}\text { It is used when it is desired to include all of the decision } \\
\text { points (alternatives) that have greater than zero values in the } \\
\text { evaluation. }\end{array}$ \\
\hline $\begin{array}{l}\text { Type } \| \\
\text { (UType) }\end{array}$ & q & $=\left\{\begin{array}{l}0, \\
1,\end{array}\right.$ & $\left.\begin{array}{l}x \leq q \\
x>q\end{array}\right\}$ & $\begin{array}{l}\text { It is used only when it is desired to use a preference from } \\
\text { the decision points having the values above the specified q } \\
\text { parameter (threshold value). }\end{array}$ \\
\hline $\begin{array}{l}\text { Type III } \\
\text { (VType) }\end{array}$ & $q, p$ & $=\left\{\begin{array}{l}0 \\
\frac{x}{p} \\
1\end{array}\right.$ & $\left.\begin{array}{r}x \leq q \\
q<x<p \\
x \geq p\end{array}\right\}$ & $\begin{array}{l}\text { It is ensured that decision points having values in the interval } \\
(q, p) \text { are not neglected and evaluated in addition to using } \\
\text { the decision point having the values above the determined p } \\
\text { parameter (threshold value). }\end{array}$ \\
\hline $\begin{array}{l}\text { Type IV } \\
\text { (Level } \\
\text { Type) }\end{array}$ & $q, p, y$ & $=\left\{\begin{array}{l}0 \\
y \\
1\end{array}\right.$ & $\left.\begin{array}{r}x \leq q \\
q<x<p \\
x \geq p\end{array}\right\}$ & $\begin{array}{l}\text { It is desirable to use a preference from the decision points } \\
\text { having the values above the determined p parameter. However, } \\
\text { it is ensured that the decision points having the values in the } \\
\text { interval (q, p) are not equal to each other, so that they can be } \\
\text { evaluated to the same extent (y). }\end{array}$ \\
\hline $\begin{array}{l}\text { Type V } \\
\text { (Linear) }\end{array}$ & $q, p$ & $\left\{\begin{array}{l}\frac{0}{p-q} \\
\frac{p-q}{1}\end{array}\right.$ & $\left.\begin{array}{r}x \leq q \\
q<x<p \\
x \geq p\end{array}\right\}$ & $\begin{array}{l}\text { It is desirable to use a preference from the decision points } \\
\text { having the values above the determined p parameter. However, } \\
\text { decision points with values in the interval }(q, p) \text { are not } \\
\text { neglected, and those closer to the lower limit are provided with } \\
\text { a lower degree of preference than those near the upper limit. }\end{array}$ \\
\hline $\begin{array}{l}\text { Type VI } \\
\text { (Gaussian) }\end{array}$ & $q, p, \sigma$ & $\left\{\begin{array}{l}0, \\
1-e^{\frac{-x^{2}}{2 \sigma^{2}}} \\
1\end{array}\right.$ & $\left.\begin{array}{c}x \leq q \\
q<x<p \\
x \geq p\end{array}\right\}$ & $\begin{array}{l}\text { It is desirable to use a preference from the decision points } \\
\text { having the values above the determined p parameter. } \\
\text { However, for the values corresponding to the interval }(q, p) \text {, the } \\
\text { preference measure is reduced according to standard errors. }\end{array}$ \\
\hline
\end{tabular}

Source: Brans \&Vincke, 1985

Step 4.In accordance with predetermined preference functions, each alternative's superiority scores are calculated with pairwise comparison of the alternative to others, according to each criterion using the equation 1. Superiority scores are illustrated in Figure 1.

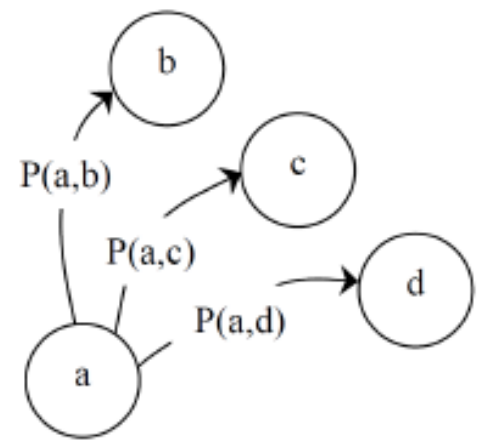

$\Phi^{+}(\mathbf{a})$

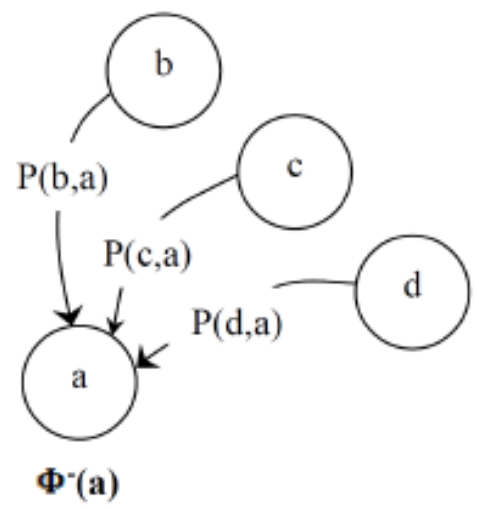

Figure 1: Determining the positive and negative scores Source: Dağdeviren ve Eraslan, 2008: 71. 


$$
P_{j}(a, b)= \begin{cases}0, & f(a) \leq f(b) \\ p[f(a), f(b)], & f(a)>f(b)\end{cases}
$$

where;

$f(a)$ :The performance value of alternative $a$ under the criterion $\mathrm{j}$ on the initial decision matrix,

$f(b)$ :The performance value of alternative $b$ on the initial decision matrix, under the criterion $\mathrm{j}$.

$P_{j}(a, b):$ The preference function for the jth criterion.

In the concrete cases for the comparison of two alternatives $a$ and $b$, depending on the difference between $f(a)$ and $f(b)$, the function $P$ is calculated as follows with equation 2 .

$$
P_{j}(a, b)=p[f(a), f(b)]=\mathrm{p}[f(a)-f(b)]
$$

Step 4 is repeated for all criteria for alternative $a$, and then for each alternative under the all criteria.

Step 5. For each alternative, the preference indexes are calculated using the equations 3 and 4 .

$$
\begin{aligned}
& \pi(a, b)=\sum_{j=1}^{n} w_{j} P_{j}(a, b) \\
& \pi(b, a)=\sum_{j=1}^{n} w_{j} P_{j}(b, a)
\end{aligned}
$$

The characteristics of the the preference index are as the following in equations 5-8.

$$
\begin{aligned}
& \pi(a, a)=0 \\
& 0 \leq \pi(a, b) \leq 1 \\
& 0 \leq \pi(b, a) \leq 1 \\
& 0 \leq \pi(a, b)+\pi(b, a) \leq 1
\end{aligned}
$$

Step 6.Calculation of positive, negative net flows for each alternatives by the equations 9-11.

$$
\begin{aligned}
& \Phi^{+}(a)=\frac{1}{e-1} \sum_{s \in K} \pi(a, S) \\
& \Phi^{-}(a)=\frac{1}{c-1} \sum_{T \in K} \pi(T, a) \\
& \Phi(a)=\Phi^{+}(a)-\Phi^{-}(a)
\end{aligned}
$$

where;

$\mathrm{K}$ : The set of all alternatives in decision problem

$\mathrm{S}$ : The set of alternatives where alternative is preferred to others

e: The number of elements in the set $\mathrm{S}$
$\mathrm{T}$ :The set of alternatives where all of alternative are preferred to the alternative $a$

c: The number of elements in the set $T$

After the calculation of net flows for each alternative, next step is applied to complete PROMETHEE process.

Step 7.Ranking the alternatives according to net flow value in descending order.

In ranking the alternatives, there are two suggested techniques by Brans and Vincke(1985):

1. Ranking the alternatives by a partial preorder

In the pairwise comparison, alternative a is preferred to alternative $b$, when one of the following conditions is satisfied.

$$
\begin{array}{cr}
\text { i. } & \Phi^{+}(\boldsymbol{a})>\Phi^{+}(\boldsymbol{b}) \text { and } \Phi^{-}(\boldsymbol{a})<\Phi^{-}(\boldsymbol{b}) \\
\text { ii. } & \Phi^{+}(\boldsymbol{a})>\Phi^{+}(\boldsymbol{b}) \text { and } \Phi^{-}(\boldsymbol{a})=\Phi^{-}(\boldsymbol{b}) \\
\text { iii. } & \Phi^{+}(\boldsymbol{a})=\Phi^{+}(\boldsymbol{b}) \text { and } \Phi^{-}(\boldsymbol{a})<\Phi^{-}(\boldsymbol{b})
\end{array}
$$

Alternative a and are indifference, when

$$
\Phi^{+}(a)=\Phi^{+}(b) \text { and } \Phi^{-}(a)=\Phi^{-}(b)
$$

Alternative $a$ is not compared to alternative $b$, when one of the following condition is satisfied.

$$
\begin{array}{ll}
\text { i. } & \Phi^{+}(\boldsymbol{a})>\Phi^{+}(\boldsymbol{b}) \text { and } \Phi^{-}(\boldsymbol{a})>\Phi^{-}(\boldsymbol{b}) \\
\text { ii. } & \Phi^{+}(\boldsymbol{a})<\Phi^{+}(\boldsymbol{b}) \text { and } \Phi^{-}(\boldsymbol{a})<\Phi^{-}(\boldsymbol{b})
\end{array}
$$

2. Ranking the alternatives by a total preorder

The alternative $a$ outranks the alternative $b$, if $\Phi(a)>\Phi(b)$.

In this study, alternatives are sorted by a total preorder. When the alternatives are sorted in descending order, the alternative at the top is selected as the best alternative considering the composite criteria computations according to PROMETHEE method.

\section{APPLICATION of the METHOD and RESULTS}

The analysis is performed using PROMETHEE GAIA software's academic edition. In the analysis, Lineer preference function is selected for all criteria and each country is given an equal weight. For all of the country, presented the ranking results of PROMETHEE have been indicated in Table 2, in the alphabetic order 
of the country names. In Table 2, 28 EU countries are ranked considering nine critera for each year to observe the performance of the countries, espacially to observe the performance of the UK. Because of space restriction, PROMETHEE scores composing PROMETHEE rankings are indicated within the parenthesis within the whole text, after here, and are not included in the Table 2.

\subsection{Comparison of the Rankings between 2010-2015 for UK and France}

In 2010, UK's ranking is 15th, but this comes with the sign of warning, performance is low with a negative score (-0.0117). UK is followed by France, again with a worry some performance, with a negative score (-0.0576). UK's position from 2010 to 2012 does not improve but slightly worsens on the basis of scores for this period. UK ranking slides two level down to become 17th- both in 2011 and in 2012. France is two level down in 2011, 18th, but return to 16th place in 2012 both with negative scores. As it is clear from standings, both UK and France are at critical levels with negative scores for three sample periods.

For the period 2013, UK's score implies small betterment in performance but still with negative score. UK gets promoted to the 14th place, two level upscale than former year. France maintains same ranking with very little improvement on its score, but a critical negative one. For the year 2014, UK performance declines visibly both on account of its score and ranking. There is a visible deterrioration on its score while ranking goes two scales down to 16th place. The deterrioration on french performance continous also in this period, bringing down France to 20th place for the first time with alarmingly low score. UK's score for the year 2015 is almost same as previous year, and appropriately maintains 16th place in ranking. For the same period, France records a small improvement but critical state is a continous one with alarmingly high negative score. France is promoted two up from 20th place to 18th place.

Table 2: Ranking Results

\begin{tabular}{|c|c|c|c|c|c|c|}
\hline \multirow[b]{2}{*}{ Alternatives } & \multicolumn{6}{|c|}{ Rankings } \\
\hline & 2010 & 2011 & 2012 & 2013 & 2014 & 2015 \\
\hline Austria & 13 & 3 & 4 & 8 & 7 & 7 \\
\hline Belgium & 6 & 5 & 10 & 13 & 14 & 15 \\
\hline Bulgaria & 21 & 22 & 24 & 25 & 25 & 23 \\
\hline Croatia & 20 & 23 & 21 & 23 & 15 & 22 \\
\hline Cyprus & 5 & 15 & 11 & 22 & 23 & 12 \\
\hline CzechRepublic & 10 & 10 & 9 & 5 & 5 & 8 \\
\hline Denmark & 9 & 4 & 3 & 3 & 4 & 4 \\
\hline Estonia & 14 & 14 & 13 & 10 & 13 & 13 \\
\hline Finland & 3 & 12 & 8 & 11 & 6 & 10 \\
\hline France & 16 & 18 & 16 & 16 & 20 & 18 \\
\hline Germany & 11 & 8 & 12 & 9 & 11 & 11 \\
\hline Greece & 26 & 28 & 28 & 28 & 28 & 28 \\
\hline Hungary & 18 & 13 & 14 & 18 & 8 & 17 \\
\hline Ireland & 7 & 9 & 7 & 4 & 3 & 3 \\
\hline Italy & 22 & 21 & 25 & 26 & 26 & 25 \\
\hline Latvia & 27 & 26 & 23 & 19 & 19 & 20 \\
\hline Lithuania & 28 & 25 & 19 & 17 & 17 & 21 \\
\hline Luxembourg & 2 & 2 & 2 & 2 & 2 & 2 \\
\hline Malta & 4 & 7 & 5 & 6 & 9 & 5 \\
\hline Netherlands & 1 & 1 & 1 & 1 & 1 & 1 \\
\hline Poland & 19 & 20 & 22 & 24 & 21 & 19 \\
\hline Portugal & 24 & 19 & 20 & 20 & 22 & 26 \\
\hline Romania & 25 & 27 & 27 & 27 & 27 & 27 \\
\hline Slovakia & 17 & 16 & 18 & 15 & 18 & 14 \\
\hline Slovenia & 12 & 11 & 15 & 12 & 10 & 9 \\
\hline Spain & 23 & 24 & 26 & 21 & 24 & 24 \\
\hline Sweeden & 8 & 6 & 6 & 7 & 12 & 6 \\
\hline United Kingdom & 15 & 17 & 17 & 14 & 16 & 16 \\
\hline
\end{tabular}


On the other hand; the briefly portrayed pictures for UK and France can be glanced through from a different angle by GAIA visual analysis for the year 2015 in the Figure 2. Additionally, other countries' performances can be reviewed through GAIA visual analysis.

Net flows (scores) of the countries have been illustrated in Figure 2 as demonstration purposes of overall picture of countries' position. Figure 2 gives the relative position of the $28 \mathrm{EU}$ countries in GAIA plane. In this plane, the similar ones are expected to have a close position to each other. Besides, countries reflecting similar performances are represented by axis orienting in similar directions. Furthermore, countries close to decision axis which reflects the PROMETHEE II ranking are considered the most effective criteria in determination of countries performances. On the other hand, criterion orienting in opposite direction compared to decision axis is considered as conflicting criterion. Last but not least, the length of the criterion axis has important implications on the position of the country, as the longer a criterion axis is, the more selective power that criterion axis has on the results.

According to the Figure 2, it can be seen from the general pattern that the UK, Belgium and Hungary are clustered in the year 2015 since their positions are substantially close to each other. Some failed countries, namely Portugal, Crotia, Bulgaria and Italy have made of another cluster showing the similarity of these countries. However, Greece is highly far away in the opposite direction of the decision axis and therefore it is the worst one. Cyprus is segregated from all other failed countries and better than the others as Belgium since it is close to the FDI outflow and inflow axises. According to the decision axis, Netherlands is in the best position in terms of composite solution. This country is followed by Luxembourg, Ireland and Denmark. Ireland and Luxembourg have better performance in foreign direct investments than Netherlands. Czech Republic and Malta have a good position for the criteria, unemployment and youth unemployment.

On the other side, as shown in Figure 2, main criteria such as GDP, material deprivation, import-export, inequality of the income distribution and work atrisk-of-poverty are in the same direction with the decision line, and dominant criteria in constructing the PROMETHE ranking. The criteria, foreign direct investments and unemployments are not dominant ratios while constructing the PROMETHEE ranking when they compared with previous ones.

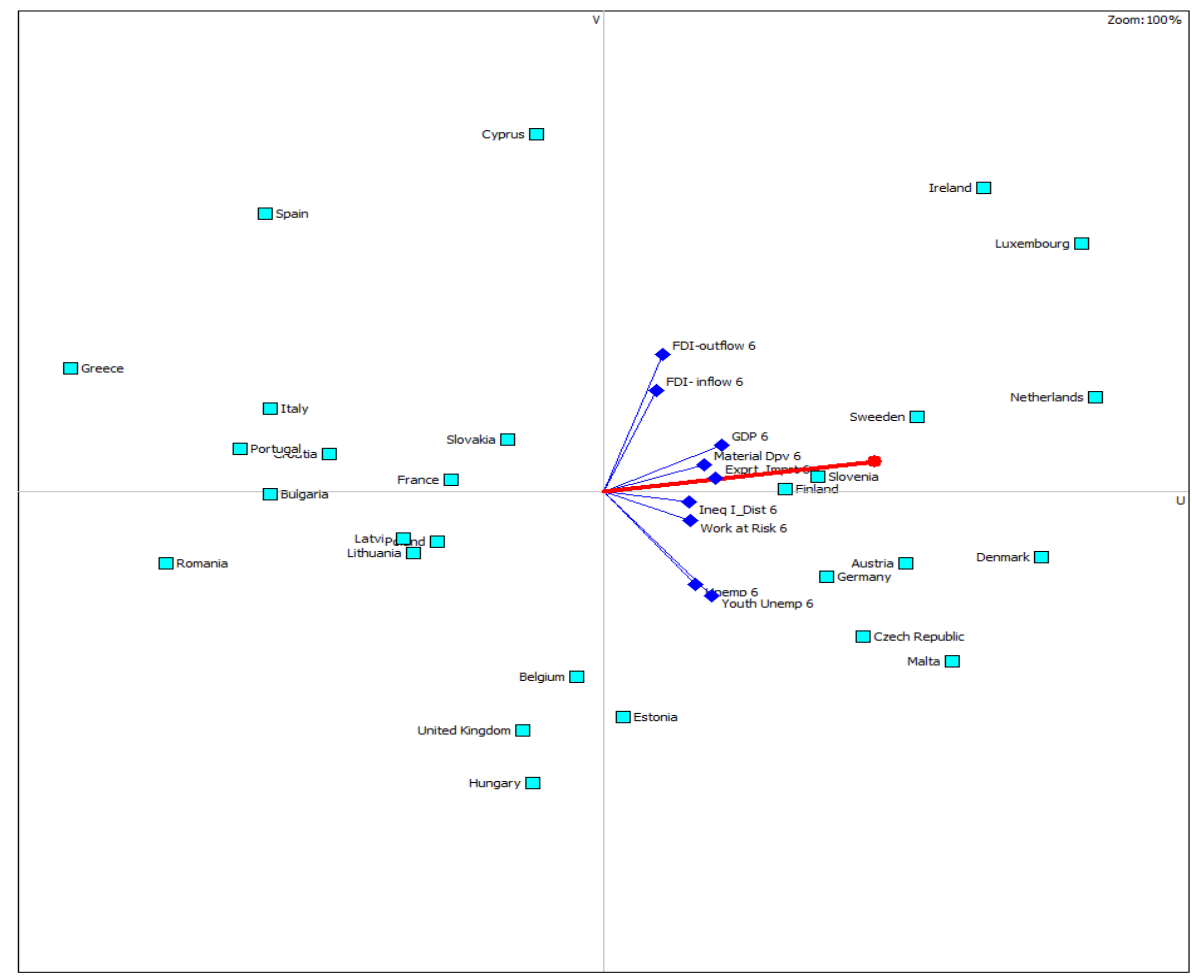

Figure 2: GAIA visual analysis for the year 2015 


\subsection{Interpretation of the Criteria Used for UK between 2010 and 2015: UK Profiles}

When graphical demonstration for each criterion is reviewed, the picture for UK becomes clearer. In Figure 3, for the year 2010, UK's overall relatively poor performance is underlined by each criterion where performances matching with negative score. UK's scores registered badly on the criteria of; FDI inflows and outflows, material deprivation, inequality of the income distribution, export-import. UK is granted positive scores based on only four criteria.

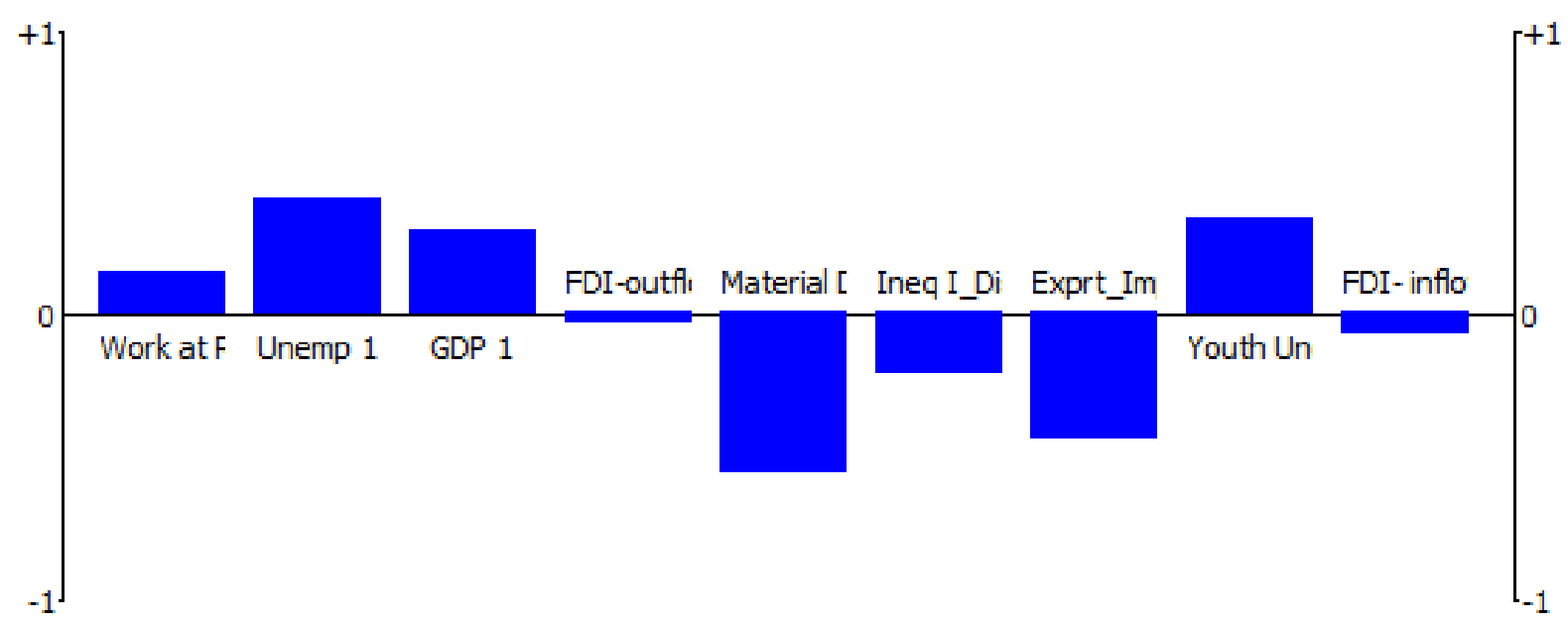

Figure 3: United Kingdom profile for the year 2010

The UK profile, in Figure 4 for the year 2011 presents a familiar picture as the previous year when the overall score is broken down into the each individual criterion. UK performs negatively on five separate critera as the former base year, but only with slight difference is that FDI outflows become of a positive value while work at poverty becomes negative.

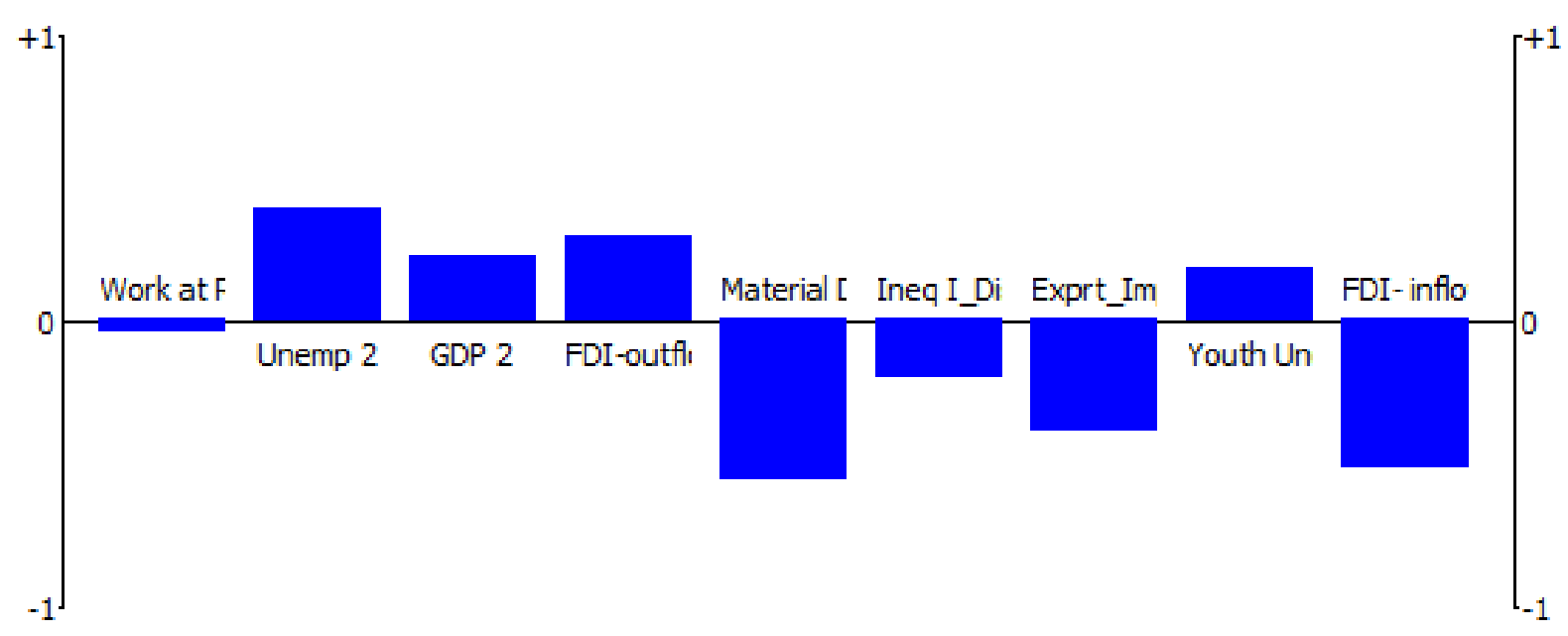

Figure 4: United Kingdom profile for the year 2011

In Figure 5 for the UK profile in 2012, the performance profile implies further deterrioration. UK performed negatively on six criteria for the first time since 2010. The negative contribution of the material deprivation and export-import becomes conspicous. FDI inflows and outflows both register negative scores. 


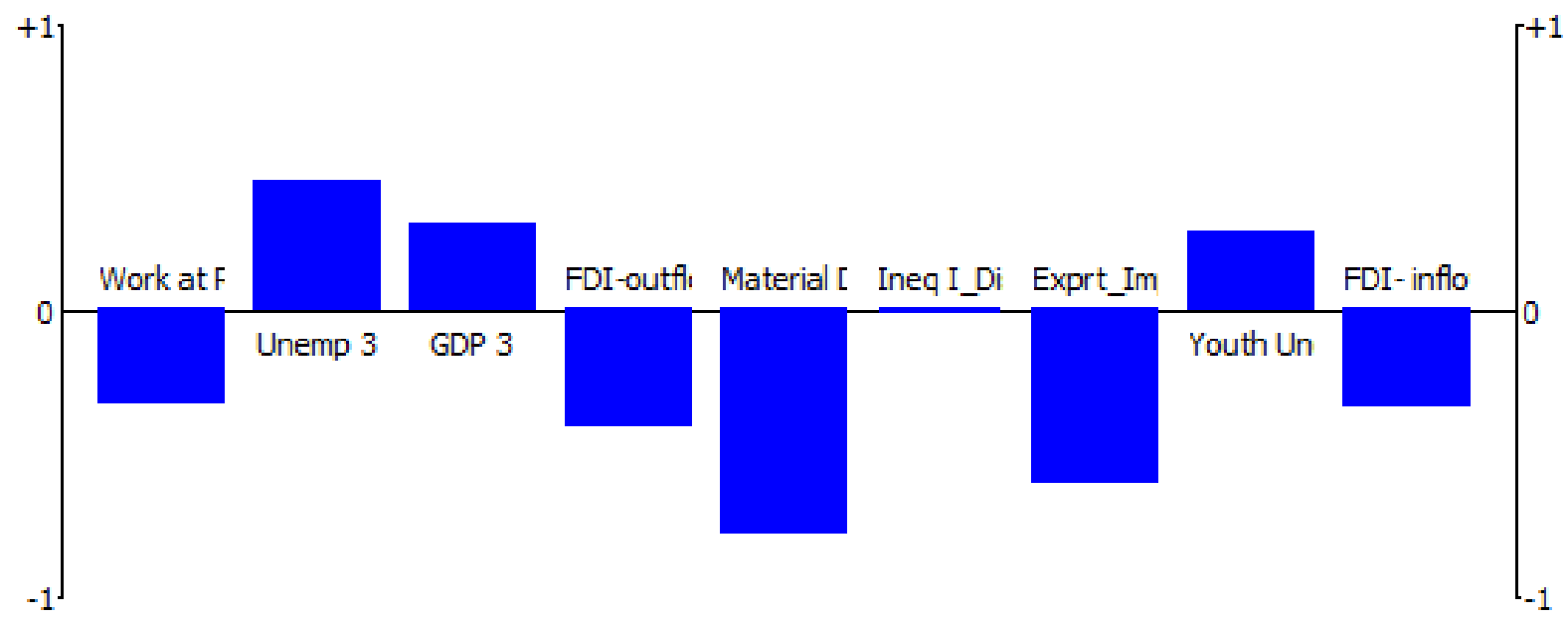

Figure 5: United Kingdom profile for the year 2012

For 2013, UK profiles indicate that, number of negative criteria for UK fall to three for this period for the first time since 2010. This outcome is associated with the improvement recorded in overall score relative to previous year. Yet, negative contribution of material deprivation and export-import is very substantial. Additionally, it appears that negative contribution of export-import has risen significantly as compared to the previous year.

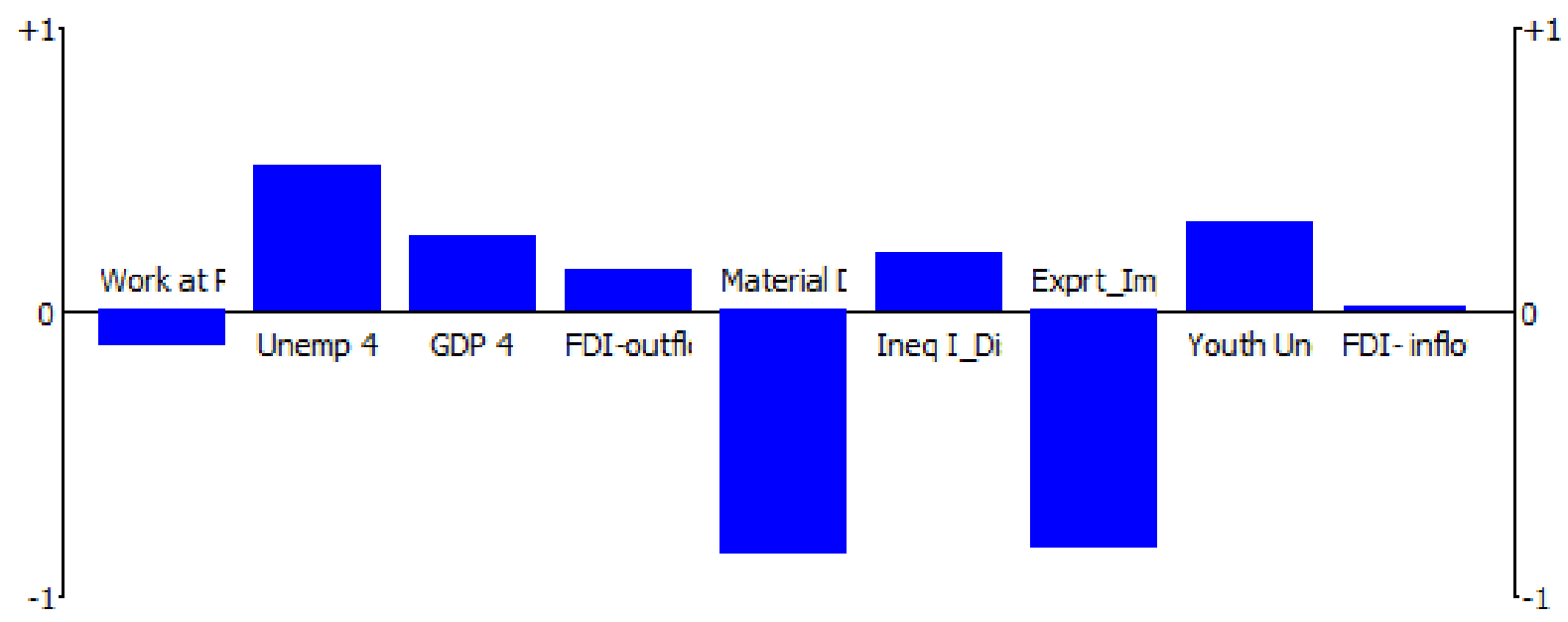

Figure 6: United Kingdom profile for the year 2013

UK's deterrioration on the overall score in 2014 is equally visible on reading from UK profile for the same year. The graph demonstrates that the number of criteria with negative scores rise from three to four in relation with the previous year. An outsanding negative contribution of FDI-outflow, material deprivation and export-import are the defining features the period concerned. 


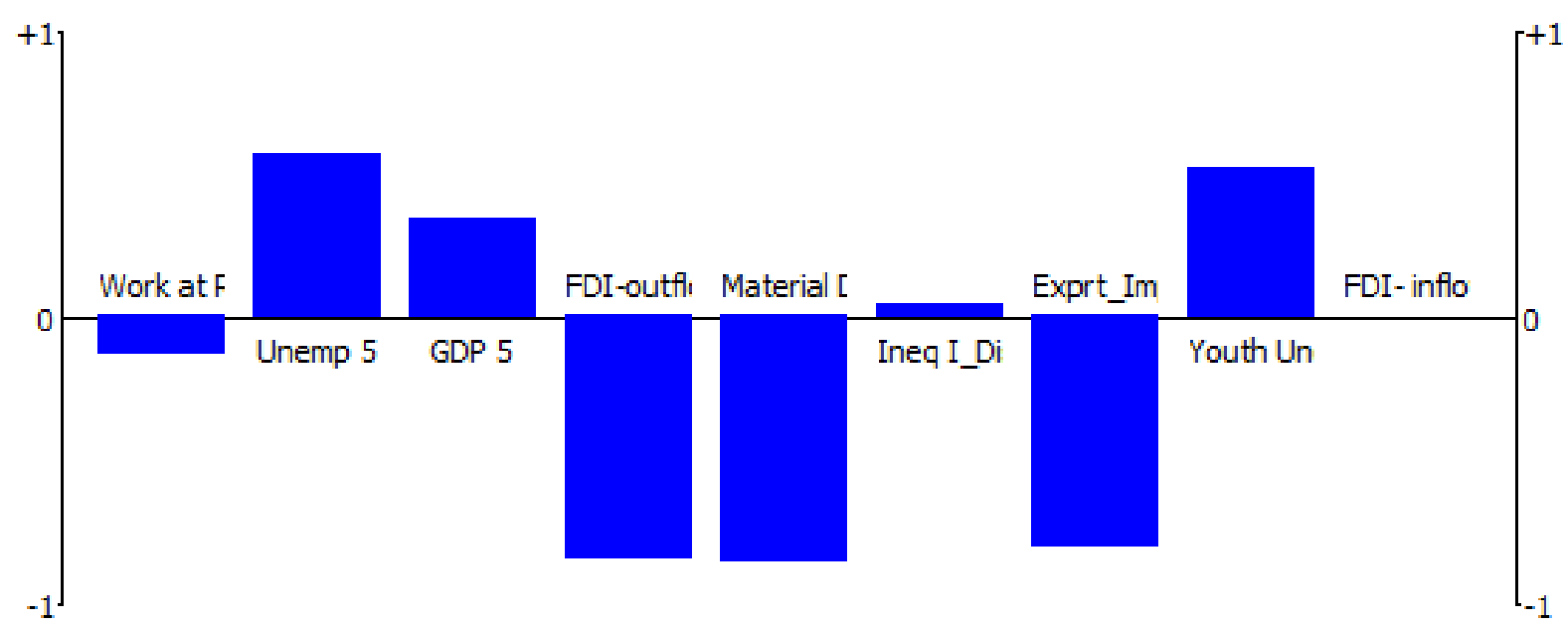

Figure 7: United Kingdom profiles for the year 2014

As shown in Figure 8, concerning the year 2015, final year in the sample period, the overall performance appears to be almost same as the preceding year. UK profile for the same year also displays similar pattern as compared to the previous year.

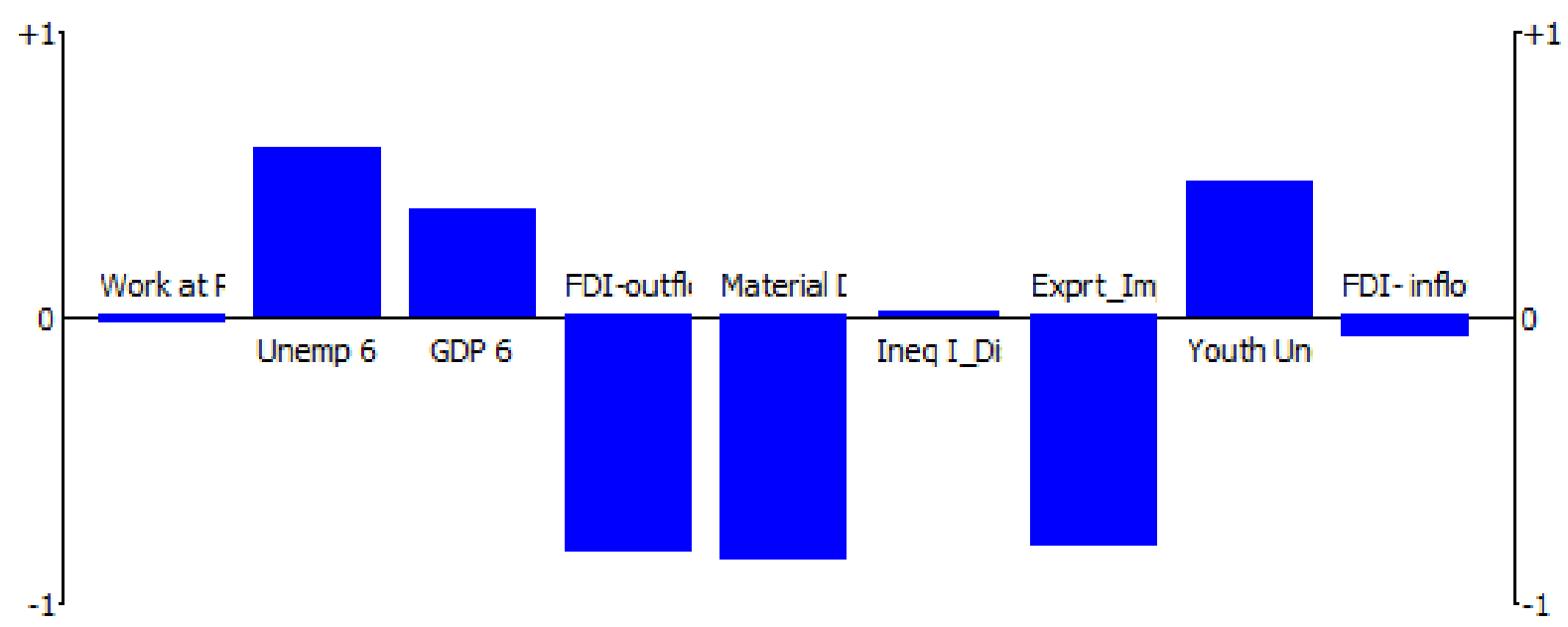

Figure 8: United Kingdom profile for the year 2015

Regarding wages or real income for employees, on aggregate, there is a visible deterioration in the course of past decade. It is a crucially important finding is that such declining pattern is partly due to the structural setbacks intented in UK labour markets. The laws and regulations in practise have gradually become less and less favourable for workers of those starting a new job.

Contractual obligations by employers have been eased off over the time, short tenure contracts have become more of a common practise in labour market. This tendency yields a significant leverage for employers in order to fire workers without any justifiable reason with regard to employees' commitment for the job. Developments as such triggered a vicious cycle in through which employees' protection is compromised together with weakened powers of labour unions. This process itself alone has created a strong impact on wage-income to inflict substantial loss of income over the time. Similar patterns and practises are also wide spread in many other EU member countries.

\subsection{Comparing the Performances of the UK with the Highest Scoring Countries for 2010- 2015}

The extent of economic troubles in UK are very much concern of this investigation. To highlight the UK's case under the context of EU and EU economies, it is insight- 
ful to compare the performances of UK and Netherlands since the latter has become best performing country through the all of the sample period between 2010 and 2015. For the 2010, Netherland holds the highest score (0.6539), and occupies the first place in ranking. UK score for this period is a negative small number $(-0.0117)$ and placed as 15th in ranking table, Table 2 above. There is a huge gap between the performance score of Netherlands and UK for the sample period of 2010 and similar trend can be inferred through reading the scores of each country for the entire period. The striking gap in performances of these two countries can be comprehended more systematically viewing through the graphical versions of performances for each criterion. Through experimenting this, the reader is enabled to compare the each criterion to see how big difference has become regarding UK and Netherland. Netherland profiles are shown in Figure 9 and Figure 10. For all years, Netherland has aggregated positive scores with the most of criteria and becomes the first country in ranking lists, in Table 2 above.

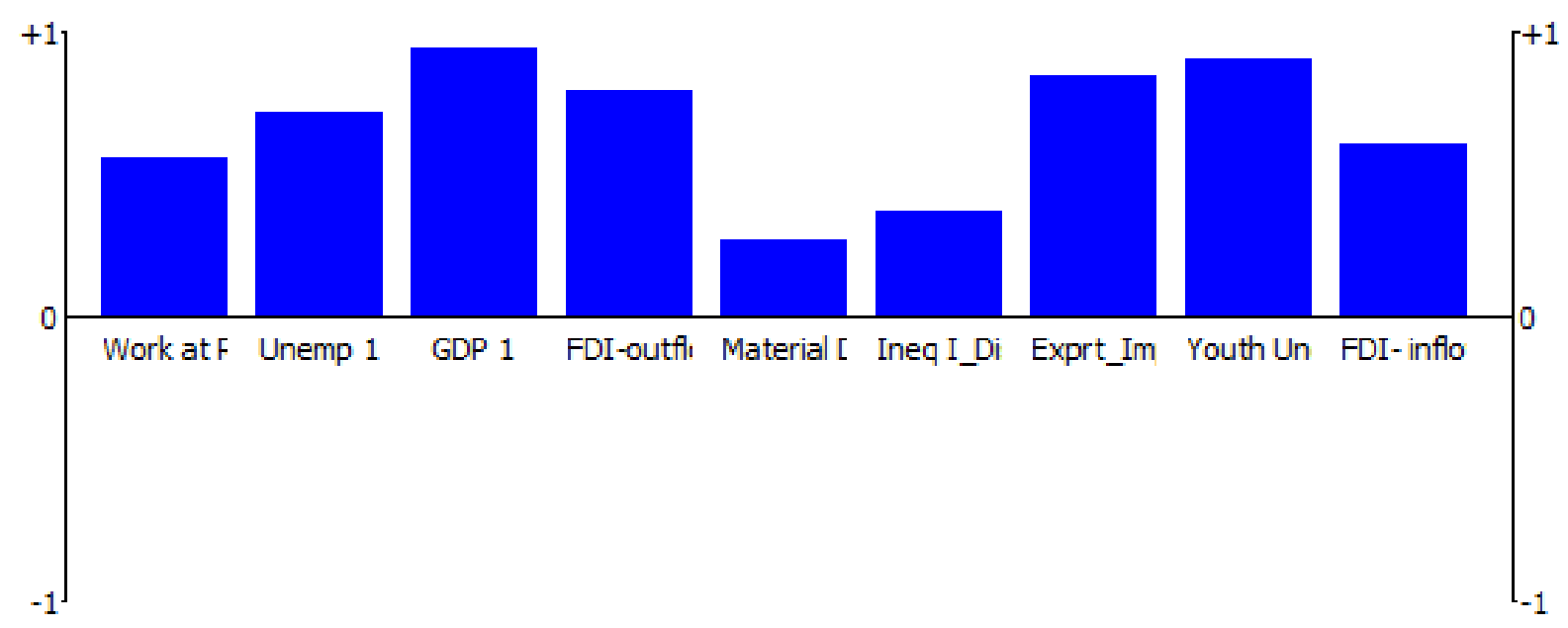

Figure 9: Netherland profile for the year 2010

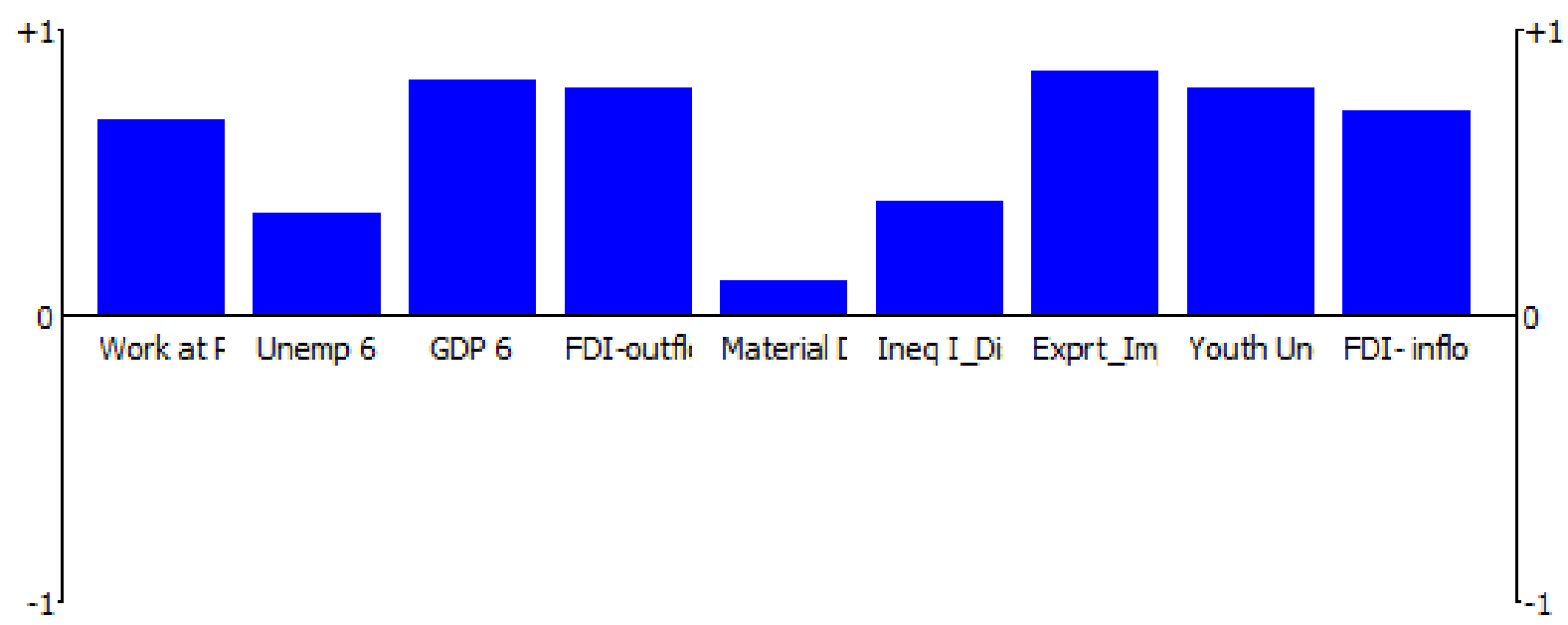

Figure 10: Netherland profile for the year 2015

In Table 2 above, UK is 15th in ranking in 2010but in 2013 UK's performance (score) is lower while its ranking position is upward moving. This pattern tells that UK has upgraded its standing but not her performance-promoted in rank and fallen in scoreoccured at the same time. Similarity can be drawn with Netherlands, 2011 achieved level of score is constantly in decline for the susequent periods except for the year 2013. Even after reaching a peak in 2013, succesive years report significant fall in scores. As for the second ranking Luxembourg, it has experienced continual fall in scores since 2012. Finland, not only 
far from the 2010 ranking (3rd) in 2015 (10th) but its performance score has almost fallen immensely from 2010 to 2015 In 2010, Finland holds the 3rd place with the score of 0.4313 but relegated to 10th place in 2015 with a dramatically reduced score of 0.2487 . Parellell patterns can be observed with most of the remaining sample countries, improvement in a country's ranking does not necessarily coincides with improvement in its performance. As for the Germany, lingering around the ranking ranging between 8 th and 11 th place over the time, finally remains at 11 th place, which is not perfect match for the Germany (2015 score is 0.2312 ).

Similar comparisons can be derived for those countries that have been heavily immersed in economic turmoils -through reading their overall scores, viewing graphical portrayals to interpret the each criterion, through reading the implications of GAIA visual analysis. The case of UK and other related issues have been covered so far with the attention is mainly focused on the case of UK. Before concluding this part; it is rather crucial emphasizing the case of worst performing countries. These are very well known in public domain, bottom five least scoring countries: Spain, Italy, Portugal, Romania and Greece for the final sample year of 2015.

The economic troubles in those countries have been accelerating for long without much hope left for the long-awaited turnarounds. Again, those tendencies and crisis quoted are the biggest obstacles that undermine the very challenges of European integration process.

With the Figure 11 and Figure 12, the profiles of the last two countries; Romania and Grecee are indicated in in order to observe the contribution to the PROMETHEE scores of each criterion for the year 2015. As shown in the figures, the contributions of the criteria are mostly negative on the aggregated score for these countries.

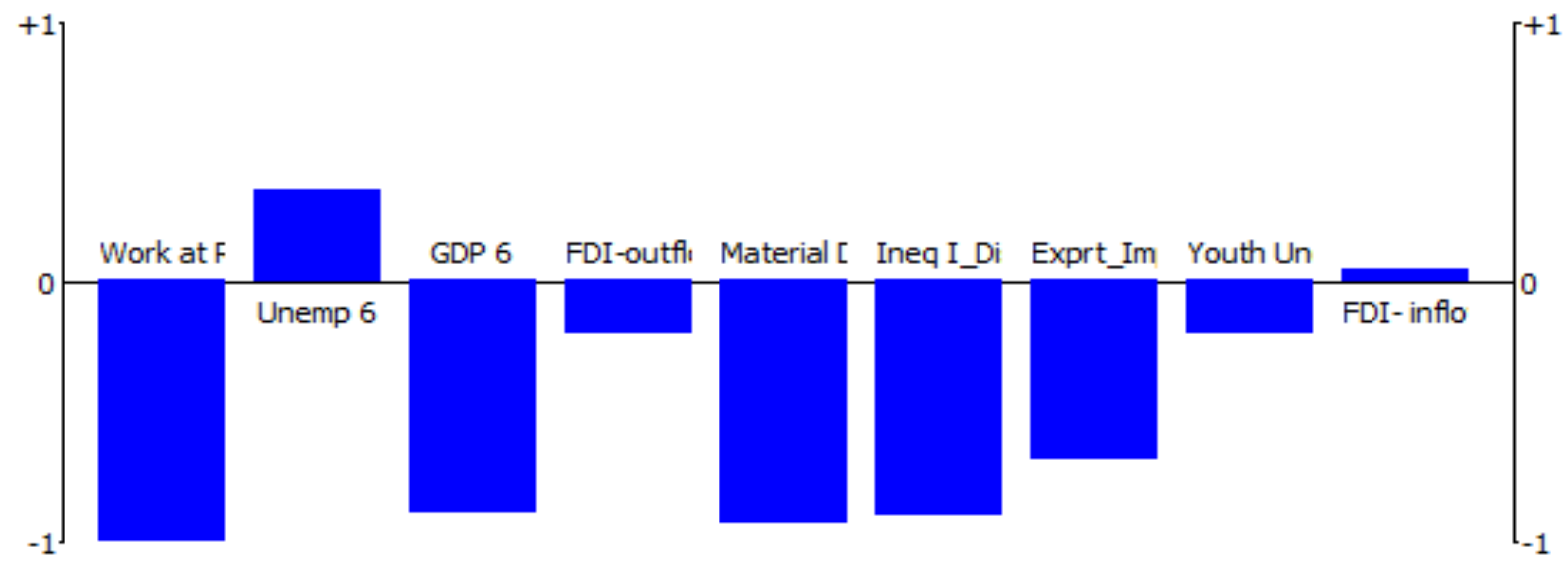

Figure 11: Romania profile for the year 2015

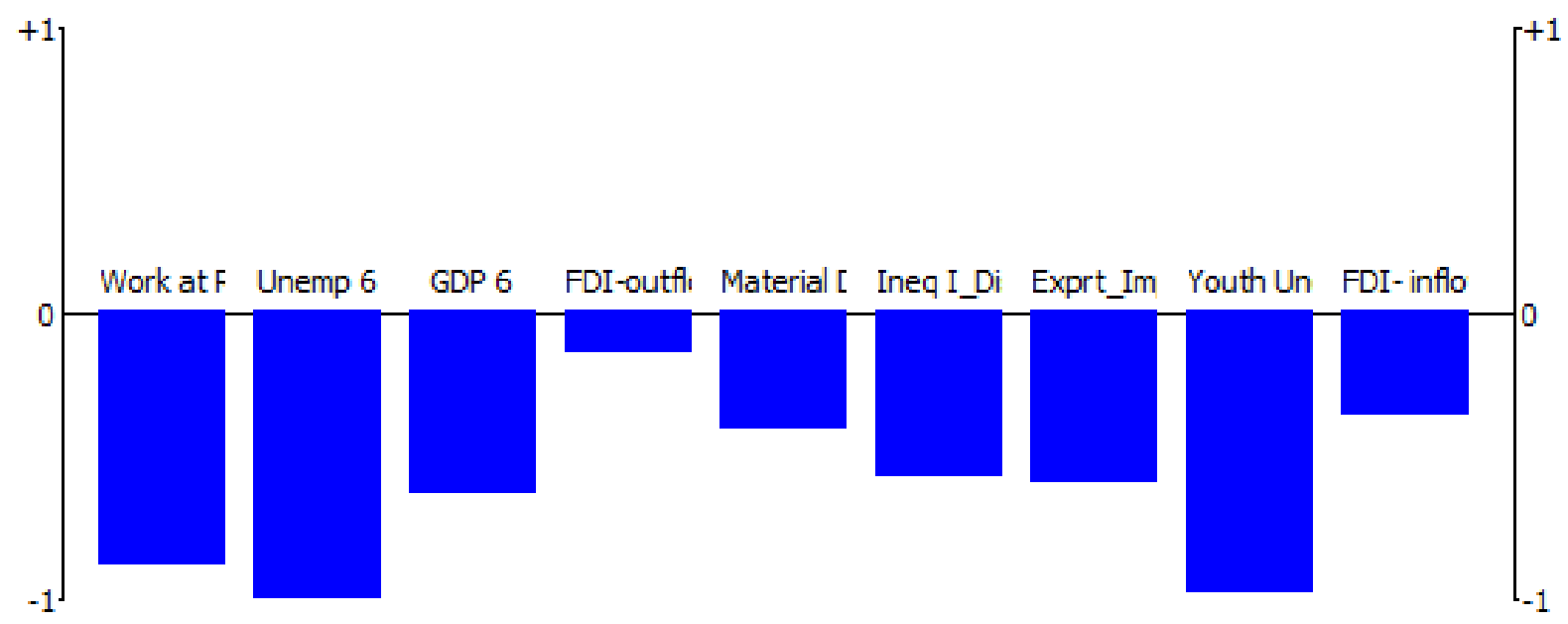

Figure 12: Greece profile for the year 2015 


\subsection{Comparison between 2010-2015: Viewing Through the Lenses of GAIA Visual Analysis}

UK's position from 2010 to 2015 does not improve but slightly worsens on the basis of its actual scores concerning this period. France's relative performances have also gradually deterriorated during this given sample period. Contribution of the criteria for the overall performance are relatively similar during 2010 and 2015, neither France nor UK happen to register improvement in most of the criteria conserned. This case is directly reflected in the distribution of their own scores for UK and France.

This tendency can be detected from GAIA visual analysis in Figure 2. It allows the reader to visualize the spread of the relevant performances as revealed. In the same fashion, other countries' positions can also be viewed for evaluating and comparing their performances. The compact way of utlizing GAIA visual analysis can at least provide us with the crude picture of economic instability besieges a great number of EU members. Sixteen countries are included in danger zone-the very economic crisis can easily help shaping public opinion. When viewed from this light; together with some other factors, economic deterrioration and its reflection on ordinary people's standards of living can be arbirtrarily translated into strong anti-European sentiments, built-in reflexes and reactions; and even reactionary radical movements. It is incumbent upon the politicians, bureaucrats and EU decision makers and other high ranking EU officials to evaluate the root causes of such troubles repeatedly without any sign of dispair. Constructive steps should be taken in the direction of finding remedy without any delay and with full coordination, cooperation and collobration among the countries and competent bodies of EU. European leaders are expressing their resolve to maintain and prosper the united Europe; but in order to keep Europe united the people of Europe are impatiently awaiting to observe immediate results, rather than hearing wishes and fancy talks of unity.

\section{CONCLUSION}

UK economy has long been facing difficult challenges after the major setbacks and instabilities in the core of the domestic economics acummulated over the years. The results of this research paper points to the fact that UK has been stuck in arrays of economic hardships which is visible in basic arithmetics in economics but often taken to the backburner by the politicians. There revealed two major source of weakneses in UK economy -first of the indicators which approximates the cases of degree of equality, general well-being or fair distribution of income- the results in this line is disastrous for UK which is ironically a proud representative of the club of the wealthy, "G-7". The results between 2010-2015 reminder of this reality which is drawn on the facts of the statistics. None of the sample period mentioned above has represented a major step forward for more equal and prosperous economy. The 2015 results on the criteria of "in work at-risk-of-poverty rate" and "inequality of income distribution" are at critical point around the "zero" demarcation line, while "severely materially deprived people" criterion hits a catastrophic high negative, approximating "-1".

Concerning the other criteria directly reflecting some aspect of real economic activity, the real picture is an undesirable outcome once again. The crucial indicators FDI net inflows, FDI net outflows, export-import present negative values for the UK. While FDI inflows record a moderate (-) value, the case for FDI outflows is exceptionally on the negative side, edging towards -1. A parallel deterrioration can be observed with the value of export-import of, of which value is heading towards $(-1)$.

On the other hand; the scores of unemployment, youth unemployment and GDP are heading towards positive but relatively "moderate" (+) value, yet far from being large enough to outweight the negative effects of the other criteria mentioned above. Therefore, overall health of the economy is sending alarming signalls-with 2015 overall results highlighting a disastrous negative outcome. The core issue of responding to the question of whether Brexit decision was "economic one" or "political" one becomes easier in the light of findings. Under this reasoning, the UK public has made their choice in the way that they thought they had understood the economic reality correctly-the emerging result is that majority of the UK public voted against staying within the $\mathrm{EU}$, and most of those voted against were disappointed with domestic economic outcomes and they thought most of the undesirable outcome was directly linked to the relevant EU membership. Hence conclusion is that the decision to leave is mainly economically motivated decision and the reasons for UK to exit the EU are economic.

Regarding other economies, most of the countries do not seem to have real signs and indications of a prosperous healthy welfare state. France is a case in this line, producing disasrous performance between 2010-2015-deterrioration can be felt from different di- 
mensions reading through the selected criteria. France has experienced anti-European sentiments which were deepened around the time for the double round French presedential elections. It looks like anti-European public mood is settled down or anti-Europeans feel suppressed-but France, once championing almost every integration efforts in Europe-can become further involved in economic and political crisis in the future and this can easily be transformed into fierce-challenging anti European movements.

The likewise risks can threaten other EU countries especially those who hit hardest by the latest economic crisis and trying to come to terms with macroeconomic mismanagement. Southern member countries have long signalling precarious threshold reached not only on the infamous debt to GDP count but on most of othe counts. The case of Greece has gone out of control to the extent that consideration of a possible Greek exit from Eurozone has not only become an heated debate in Greek political circles but also was being treated as a serious matter and/or option in some other European circles at the hight of bail-out negotiations. Can any other coountry or countries follow the path of UK and hold referendum on EU membership? It is difficult to predict in precision but certainly cannot be ruled for certain given the staggering performances of the most EU members. Legitimate political inititatives can be considered as part of the democratic process-i.e. allowing for public to vote for whether to stay as a member of EU or leave the union.

On the other hand; there is a message both for EU leaders and member country politicians that must be read carefully. The economic decline is easily tranformed into social instability and disorder which is a threat for the future European integration process. Key to restoring faith in the EU and future of political integration is to restore the credibility of governance at domestic and EU level through rapid improvements in economic well-being of the EU citizens across the Europe. The masses across the Europe are exasparated with their unaltered position of being obliged to cope with the gradually declining economic and social welfare level together with the accommpanying restrictive austerity measures.

\section{Acknowledgement}

A first version of this article was presented at the EconWorld2017 - The sixth international conference in economics, in Paris and published in abstract form. The authors would like to thank Scientific Research Projects Unit of Çukurova University for its valuable support. 


\section{REFERENCES}

Bank of England (2015), "EU Membership and Bank of England" Bank of England Weekly Report 21 October, https://www.bankofengland.co.uk/-/media/ boe/files/speech/2015/eu-membership-and-thebank-of-england-pdf (15.5.2017)

Brans, J.P. and Vincke, P. (1985) "A Preference Ranking Organization Method" Management Science, 31(6): 647-656.

City of London (2013) 'Switzerland's Approach to EU Engagement: A Financial Services Perspective', Centre for Swiss Politics, University of Kent, Special Interest Paper, 1-14. https://www.cityoflondon.gov. uk/business/economic-research-and-information/ research-publications/Documents/research-2013/ Switzerlands-approach-to-EU-engagement.pdf (14.6.2017)

Dağdeviren, M. and Eraslan, E. (2008) "PROMETHEE SıralamaYöntemi ile Tedarikçi Seçimi" Gazi Üniversitesi Mühendislik-Mimarlık Fakültesi Dergisi, 23(1): 69-75.

Emmerson, C., Johnson, P. Mitchell, I. and Phillips, D. (2016) "Brexit and the UK's Public Finances", Institute for Fiscal Studies, IFS Report 116, 1-80. https://www. ifs.org.uk/uploads/publications/comms/r116.pdf (5.5.2017)
HM Treasury (2016) "HM Treasury Analysis: The LongTerm Economic Impact of EU Membership and the Alternatives" https://www.gov.uk/government/ publications/hm-treasury-analysis-the-long-termeconomic-impact-of-eu-membership-and-the-alternatives (2.3.2017)

House of Commons (2013) 'Leaving the EU', Research Paper 13/42, 1-112. https://beta.parliament.uk/ search?q=leaving+the+EU (12.5.2017)

PwC (2016) "Leaving the EU: Implications for the UK Economy" Price Water House Coopers (PwC) Report, https://www.pwc.co.uk/economic-services/assets/ leaving-the-eu-implications-for-the-uk-economy. pdf (2.3.2017)

Saunders, M., Fordham, T., Subbs, J., Lorenzen,H., Roy, R., Schulz, C., Searle, J., Goves, P., Amin, A. and Fahyn J. (2016) "Brexit Risk: Implications for Economies and Markets" Citi Europe Research-Economics https:// www.citivelocity.com (23.6.2017).

Özdağoğlu, A. (2013) "Üretim İşletmelerinde Lazer Kesme Makinelerinin PROMETHEE Yöntemi ileKarşılaştırılması" UluslararasıYönetim Iktisat ve İşletme Dergisi, 9(19): 305-318. 